Original Research Paper

\title{
Penerapan WISH (Wick System Hydroponic) Terhadap Kemampuan Pemanfaatan Pekarangan Rumah Warga (Studi Lapangan di Dusun Seimbang, Desa Pringgabaya)
}

\author{
Adytia Garieswara Fatahillah ${ }^{*}$, Muh. Zubair ${ }^{2}$, Baiq Nafarani Herwanda Humaera ${ }^{3}$, Dwi Reza Gunawan², \\ Siti Nur'aini ${ }^{4}$, Suci Handayani ${ }^{5}$

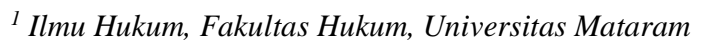 \\ ${ }^{2}$ Pendidikan Kewarganegaraan, Fakultas Keguruan dan Ilmu Pendidikan, Universitas Mataram \\ ${ }^{3}$ Akuntansi, Fakultas Ekonomi dan Bisnis, Universitas Mataram \\ ${ }^{4}$ Hubungan Internasional, Fakultas Ilmu Sosial dan Politik, Universitas Mataram \\ ${ }^{5}$ Fisika, Fakultas Matematika dan Ilmu Pengetahuan Alam, Universitas Mataram
}

https://doi.org/10.29303/jpmpi.v3i2.901

Sitasi: Fatahillah, A. G., Zubair, M., Humaera, B. N. H., Gunawan, D. R., Nur'aini, S., \& Handayani, S. (2021). Penerapan WISH (Wick System Hydroponic) Terhadap Kemampuan Pemanfaatan Pekarangan Rumah Warga (Studi Lapangan di Dusun Seimbang, Desa Pringgabaya). Jurnal Pengabdian Magister Pendidikan IPA, 4(3)

\author{
Article history \\ Received: 19 Juli 2021 \\ Revised: 31 Juli 2020 \\ Accepted: 18 Agustus 2021 \\ *Corresponding Author: Adytia \\ Garieswara Fatahillah, Ilmu \\ Hukum, Fakultas Hukum, \\ Universitas Mataram; \\ Emai: \\ adityaboma3@gmail.com
}

\begin{abstract}
Penelitian telah dilakukan oleh Mahasiswa Kuliah Kerja Nyata (KKN) Tematik Universitas Mataram tahun 2021 tentang Penerapan WISH (Wick System Hydroponic) Terhadap Kemampuan Pemanfaatan Pekarangan Rumah Warga di Dusun Seimbang Desa Pringgabaya, Kecamatan Pringgabaya, Kabupaten Lombok Timur, NTB. Penelitian ini bertujuan untuk mengedukasikan kepada masyarakat tentang metode Hidroponik untuk menanam sayur mayur di pekarangan rumah. Berkaitan dengan upaya ketahanan pangan daerah, karena perkembangan penduduk yang tidak dapat diprediksi setiap tahunnya mengakibatkan lahan penduduk yang semakin sempit dan padatnya penduduk suatu wilayah dapat menyebabkan minimnya lahan pemukiman warga. Oleh karena perkembangan penduduk semakin pesat dan lahan pemukiman warga semakin sempit, akan sulit untuk melakukan budidaya sayur mayur, kecuali dengan menggunakan metode tertentu seperti Hidroponik. Penelitian ini dilakukan dengan tahap awal penyuluhan system Hidroponik kepada warga dan dilanjutkan dengan penanaman bibit hingga perawatan. Hasil yang didapatkan dengan menyebarkan kuesioner evaluasi pelaksanaan. Kuesioner dibagikan kepada 30 orang warga Dusun Seimbang, Desa Pringgabaya, Kecamatan Pringgabaya. Dari jawaban kuesioner tersebut bahwa warga yang memiliki pemahaman awal tentang HIdroponik sebesar 2.72 yang tergolong rendah. Keefektifan penggunaan pekarangan rumah untuk budidaya sayur mayur senilai 5.45 yang tergolong sangat tinggi. Kepraktisan dan keefektifan senilai 4.84 yang tergolong tinggi. Gangguan hewan peliharaan di pekarangan rumah senilai 3.03 yang tergolong sedang. Pemanfaatan metode WISH senilai 3.93 yang tergolong sedang. Keinginan untuk melanjutkan dan mencoba Kembali budidaya sayur mayur dengan metode hidroponik WISH senilai 5.15 yang tergolong sangat tinggi. Percepatan pertumbuhan dengan penambahan nutrisi senilai 5.15 yang tergolong sangat tinggi.
\end{abstract}

Keywords: Hidroponik; WISH. 


\section{Pendahuluan}

Nusa Tenggara Barat merupakan wilayah ke-10 penghasil lumbung pangan terbesar di Indonesia, salah satu wilayah yang mendukung NTB memperoleh posisi tersebut adalah Kabupaten Lombok Timur. Menurut Kementerian Pertanian Republik Indonesia (2020), Kabupaten Lombok Timur dapat dikatakan sebagai penghasil lumbung pangan utama, hal tersebut didukung oleh kondisi alam serta kearifan lokal yang masih sangat terjaga. Dalam hal ini perlu didukung oleh Pemerintah Daerah dan setiap elemen masyarakat untuk menciptakan suatu kondisi masyarakat yang sejahtera dalam hal kebutuhan konsumsi pangan yang dapat ditemui dengan mudah (Committee on World Food Security, 2005). Seiring berjalannya waktu pemekaran wilayah berjalan semakin pesat, kepadatan penduduk juga semakin pesat. Desa pringgabaya merupakan salah satu desa yang berada di Kecamatan pringgabaya merupakan desa yang baru-baru ini telah melakukan pemekaran dengan penambahan dusun baru. Adanya pemekaran desa dikarenakan penambahan jumlah penduduk dan otonomi daerah (Stamoulis dan Zezza, 2003) Perkembangan penduduk yang tidak dapat diprediksi setiap tahunnya mengakibatkan lahan penduduk yang semakin sempit dan padatnya penduduk suatu wilayah dapat menyebabkan minimnya lahan pemukiman warga (Christina, 2019). Oleh karena itu untuk melakukan budidaya sayur mayur di pekarangan rumah memiliki peluang yang kecil jika tidak menggunakan metode-metode tertentu. Budidaya sayur mayur dilakukan agar dapat menjaga kestabilan pangan warga, dengan ketersediaan bahan pangan yang mudah terjangkau (World Bank, 1986).

Kebutuhan masyarakat dalam hal pangan setiap tahun semakin meningkat. Salah satu cara agar kebutuhan masyarakat dapat terpenuhi dan tidak bergantung hanya dari membeli sayur di pasar atau swalayan, metode penanaman menggunakan metode Hidroponik menjadi salah satu alternatif untuk menanam sayur mayur di halaman rumah atau tempat yang dapat dijadikan tempat untuk menanam. Hidroponik merupakan metode yang dapat digunakan untuk memberdayakan sayur mayur tanpa membutuhkan banyak lahan. Hidroponik sendiri diambil dari bahasa Yunani yaitu Hydro yang artinya air dan ponos yang artinya daya. Sehingga ketika dua kata tersebut disatukan akan membentuk pengertian budidaya tanaman dengan memanfaatkan air tanpa menggunakan tanah menjadi media tanam. Meskipun ditanam di dalam air, namun tumbuhan yang dibudidayakan dengan teknik ini membutuhkan lebih sedikit air, sehingga penamaan hidroponik ini sangat cocok dicoba pada daerah yang memiliki pasokan air minum. Hal ini membuat parameter seperti nutrisi, pengendalian hama, dan pencahayaan lebih mudah dikelola. Hidroponik tidak memerlukan pemakaian herbisida dan pestisida beracun sehingga lebih ramah lingkungan dan sayuran yang dihasilkan pun akan lebih sehat (Sariwati, 2019).

Pelaksanaan pemanfaatan pekarangan rumah sebagai alternatif ketahanan pangan belum banyak diketahui oleh masyarakat. Oleh karena itu perlu adanya sosialisasi dan pelatihan khusus untuk memberitahukan cara tanam sayur mayur di halaman rumah dengan metode hidroponik. Mahasiswa Kuliah Kerja Nyata (KKN) Tematik Universitas Mataram dengan tema "Ketahanan Pangan" di Desa Pringgabaya, melakukan kegiatan penyuluhan dan sosialisasi Ketahanan Pangan dengan memanfaatkan pekarangan rumah untuk menanam sayur mayur, menggunakan metode Hidroponik.

\section{Metode}

Penelitian dilakukan di Dusun Seimbang Desa Pringgabaya Kecamatan Pringgabaya, Lombok Timur. Pengambilan sampel dalam penelitian ini yaitu sampling berjumlah 30 orang yang ada di Dusun Seimbang, Desa Pringgabaya, Kecamatan Pringgabaya, Lombok Timur. Jenis data yang digunakan dalam penelitian ini yaitu Data primer adalah data pertama kali yang dikumpulkan oleh peneliti melalui upaya pengambilan data di lapangan langsung. Karena hal inilah data primer disebut sebagai data pertama atau data mentah. Data Primer diperoleh dari pengisian kuesioner yang diberikan kepada warga yang disasar dengan jumlah 30 orang Di Dusun Seimbang, Desa Pringgabaya.

\section{1) Lokasi (Dusun Seimbang, Desa Pringgabaya)}

Lokasi studi yang dipilih ialah Dusun Seimbang, Desa Pringgabaya, Kecamatan Pringgabaya, Kabupaten Lombok Timur. Lokasi dipilih didasarkan pada dekatnya lokasi dengan 
posko kelompok Kuliah Kerja Nyata (KKN) Universitas Mataram, pertimbangan jumlah penduduk yang bekerja sebagai petani dan pedagang sayur-mayur yang siap berbagi informasi mengenai penerapan sistem tanam hidroponik bagi masyarakat, termasuk pengaruh teknik tanam hidroponik tersebut masyarakat non-petani dalam upayanya menunjang ketahanan pangan di Dusun Seimbang, Desa Pringgabaya, yaitu sebagai objek penelitian kelompok mahasiswa Kuliah Kerja Nyata (KKN) Universitas Mataram.

\section{2) Populasi dan Sampel}

Populasi yang digunakan dalam peneletian ini adalah seluruh warga di RT 01 Dusun Seimbang sedangkan sampel yang digunakan adalah 30 orang warga Dusun Seimbang Desa Pringgabaya Kecamatan Pringgabaya Lombok Timur, Nusa Tenggara Barat.

\section{3) Jenis Penelitian (Metode Campuran)}

Penelitian ini menggunakan metode campuran dengan pengolahan data kuantitatif dan kualitatif. Metode campuran (Mixed Method Research) yaitu, dengan menggabungkan antara jenis penelitian kualitatif dengan kuantitatif. Menurut Maxwell (2001), metode penelitian campuran merupakan pendekatan penelitian dengan mengkombinasikan antara penelitian kualitatif dengan penelitian kuantitatif. Penelitian kualitatif bersifat subjektif peneliti melakukan interaksi secara langsung terhadap objek yang ditelitinya. Bahasa informal, menggunakan kata-kata personal.
Prosesnya induktif dan desainnya dapat berkembang/dinamis sedangkan Penelitian kuantitatif bersifat objektif, peneliti bebas dari apa yang ditelitinya Bahasanya formal berdasarkan teori dan kata-kata kuantitatif prosesnya deduktif dan desainnya statis dari awal hingga akhir.

\section{4) Data Analisis}

Hasil dari pengumpulan data primer akan diolah melalui aplikasi Microsoft Excel 2019. Dalam penelitian yang dilakukan oleh kelompok mahasiswa Kuliah Kerja Nyata (KKN) dilakukan dengan menggunakan skala likert. Skala likert digunakan untuk mengukur bagaimana responden memberikan sikap, pendapat, dan persepsi responden dalam kegiatan penelitian teknik tanam hidroponik menggunakan Wick System Hydroponic (WISH). Dalam penelitian yang dilakukan tersebut diperuntukan untuk mendapatkan respons spesifik didasarkan pada kebutuhan kelompok mahasiswa Kuliah Kerja Nyata (KKN) dalam penelitian yang dilangsungkan. Adapun jumlah pertanyaan untuk mengukur keberhasilan penelitian ini tentang penerapan Wick System Hidroponik terhadap kemampuan pemanfaatan pekarangan rumah yang terdiri atas 7 pertanyaan dan jumlah responden sebanyak 30 orang. Adapun jawaban dari pertanyaan terhadap responden kemudian dikategorikan sebagaimana terlihat pada Tabel 1 .

Tabel 1. Kategori Skor Responden dan Skor Penerapan Wish (Wick System Hydroponic) Terhadap Kemampuan Pemanfaatan Pekarangan Rumah Warga

\begin{tabular}{|c|l|c|}
\hline KETERANGAN & \multicolumn{1}{|c|}{ KATEGORI } & SKOR \\
\hline SS & Sangat Setuju & 5 \\
\hline S & Setuju & 4 \\
\hline RR & Ragu-ragu & 3 \\
\hline TS & Tidak Setuju & 2 \\
\hline STS & Sangat Tidak Setuju & 1 \\
\hline
\end{tabular}

Dalam mengukur persepsi atau respons dari responden tersebut, kelompok mahasiswa Kuliah Kerja Nyata (KKN) menggunakan 5 (lima) kategorisasi umum dalam memberikan skor terhadap bagaimana masyarakat memberikan penilaian terhadap program kerja penyuluhan teknik tanam hidroponik. Adapun skor yang dimaksud adalah tingkat tinggi, sedang, dan rendah. Pengukuran menggunakan skor ini dilakukan dengan mengaplikasikan rumus interval sebagai berikut:

Interval Kelas $(\mathrm{I})=$ Rentang $(\mathrm{R})$ : Banyak Kelas $(\mathrm{K})$

Berdasarkan rumus di atas, masing-masing skor diberikan 1,00-2,00 untuk respons skala 
persepsi dengan tingkat sangat rendah, 2,01-3,00 untuk respons skala persepsi dengan tingkat rendah, 3,01-4,00 untuk skala persepsi dengan tingkat

sedang, 4,01-5,00 untuk skala persepsi dengan tingkat tinggi, dan 5,01-6,00 untuk skala persepsi dengan tingkat sangat tinggi.

\section{Hasil dan Pembahasan}

Secara umum Penerapan WISH (Wick System Hydroponic) Terhadap Kemampuan Pemanfaatan Pekarangan Rumah di Dusun Seimbang Desa Pringgabaya dapat dilihat dari penilaian jawaban yang diberikan responden. Beberapa rangkaian kegiatan yang telah dilakukan untuk mencapai hasil adalah:

1) Penyuluhan pembuatan media tanam Hidroponik

Penyuluhan ini dilakukan untuk mengajarkan kepada masyarakat bagaimana cara tanam hidroponik, atau cara menanam tanpa menggunakan media tanah. Telah diajarkan juga bagaimana membuat media tanam hidroponik dengan memanfaatkan botol plastik bekas, agar menambah kebermanfaatan sampah plastic dan mengurangi sampah plastic di lingkungan sekitar (Max, 2021).

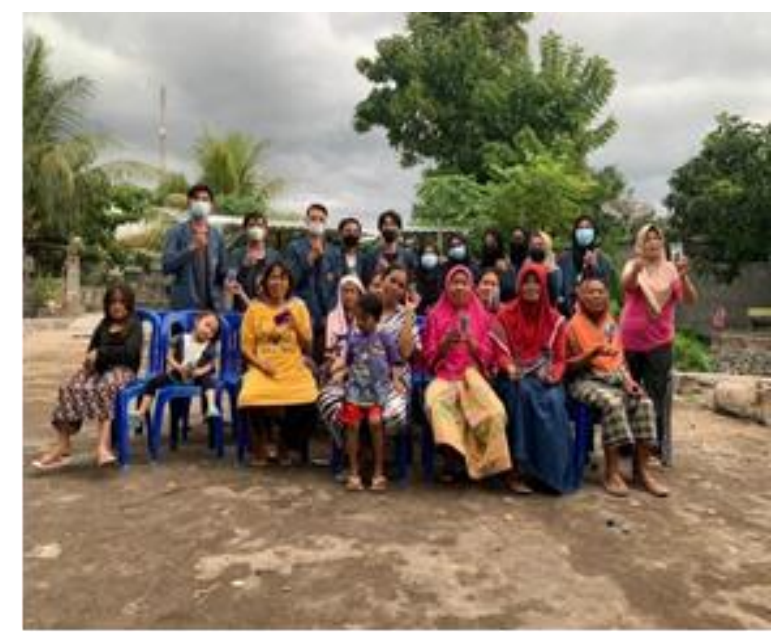

Gambar 1. Penyuluhan pembuatan media tanam Hidroponik di salah satu rumah warga di Dusun Seimbang, Desa Pringgabaya
2) Pembagian bibit tomat dan cabai kepada warga

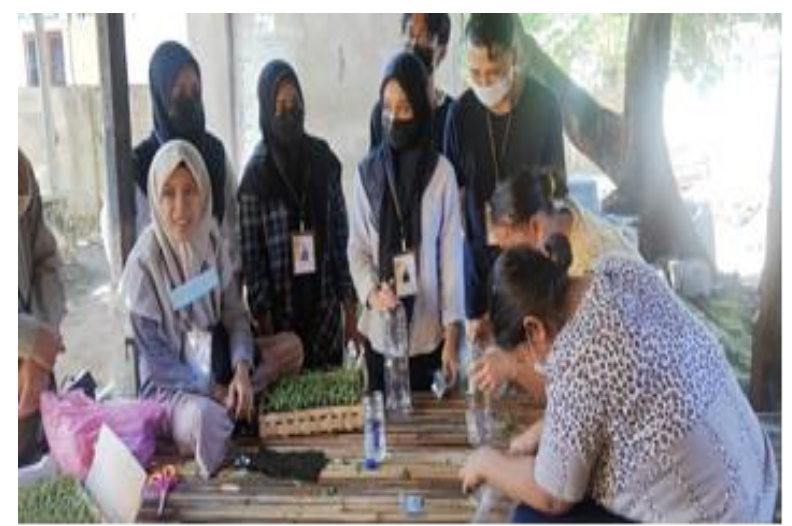

Gambar 2. Pembagian bibit tomat dan cabai kepada warga

Pembagian bibit dilakukan setelah pelaksanaan penyuluhan, agar masyarakat bisa langsung praktik menanam dengan cara Hidroponik. Bibit yang dibagikan ada dua macam jenis tumbuhan yaitu tanaman Cabai dan tanaman tomat.

3) Pemberian nutrisi dan pemantauan perkembangan tanaman

Pemberian nutrisi dilakukan dua kali dalam satu minggu, dengan rentan waktu tiga hari. Pemberian nutrisi dilakukan pada hari senin dan kamis, dengan tujuan untuk mempercepat pertumbuhan tanaman. Pemberian nutrisi dilakukan juga untuk memantau perkembangan tanaman cabai dan tomat.

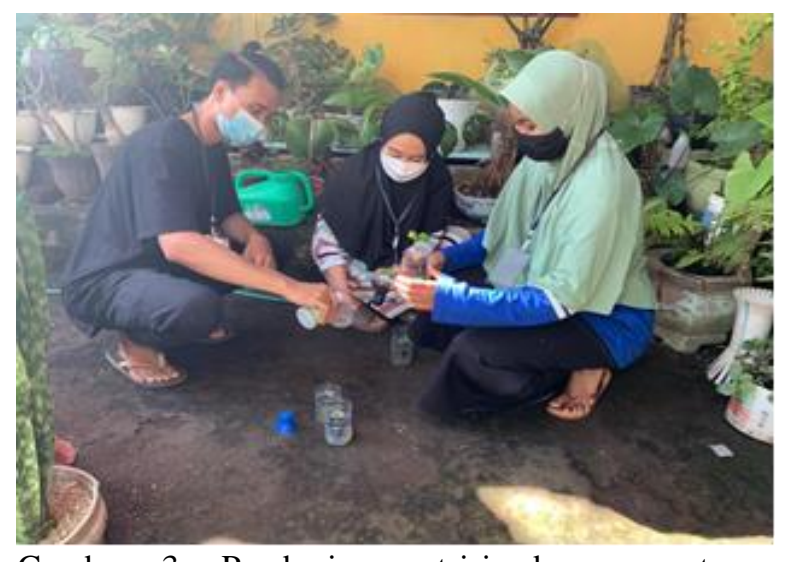

Gambar 3. Pemberian nutrisi dan pemantauan perkembangan tanaman 
4) Pembagian dan pengisian kuesioner sebagai bahan evaluasi

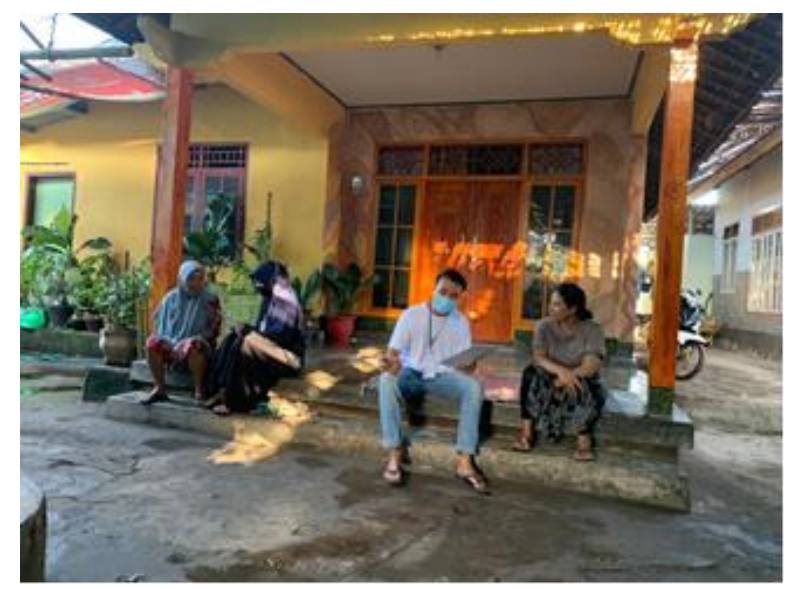

Gambar 4. Pembagian dan pengisian kuesioner sebagai bahan evaluasi
Pengisian kuisioner kepada warga ini bertujuan untuk mengevaluasi hasil penyuluhan dan praktik budidaya cabai dan tomat dengan metode Hidroponik. Pertanyaan-pertanyaan yang diajukan kepada warga mengacu pada keefektifan media tanam hidroponik. Hasil dari kuesioner dapat dilihat pada tabel 2 .

Secara umum penerapan Wick System Hydroponic (WISH) terhadap kemampuan pemanfaatan pekarangan rumah di Dusun Seimbang, Desa Pringgabaya sebesar 2,95 (hitungan kumulatif). Hal tersebut terlihat dari penilaian jawaban yang diberikan responden.

Tabel 2. Hasil Responden Penerapan WISH (Wick System Hydroponic) Terhadap Kemampuan Pemanfaatan Pekarangan Rumah

\begin{tabular}{|c|l|c|c|c|c|c|c|c|}
\hline \multirow{2}{*}{ No. } & \multicolumn{1}{|c|}{ Pertanyaan } & SS & S & RR & TS & STS & \multirow{2}{*}{ Persepsi } & Kategori \\
\cline { 3 - 7 } & & $\mathbf{5}$ & $\mathbf{4}$ & $\mathbf{3}$ & $\mathbf{2}$ & $\mathbf{1}$ & & Rendah \\
\hline 2 & Pengetahuan tentang hidroponik & 6 & 9 & 7 & 0 & 8 & 2,72 & Sangat Tinggi \\
& $\begin{array}{l}\text { Pemanfaatan pekarangan rumah (lahan } \\
\text { sempit) }\end{array}$ & 18 & 11 & 0 & 1 & 0 & 5,45 & Tinggi \\
\hline 3 & Kepraktisan dan efektif & 10 & 16 & 3 & 0 & 1 & 4,84 & Sedang \\
\hline 4 & Gangguan hewan peliharaan & 12 & 6 & 7 & 3 & 2 & 3,03 & Sedang \\
\hline 5 & $\begin{array}{l}\text { Pertumbuhan tanaman cepat dengan } \\
\text { metode WISH }\end{array}$ & 5 & 12 & 13 & 0 & 0 & 3,93 & Sangat Tinggi \\
\hline 6 & Keinginan mencoba kembali & 17 & 7 & 6 & 0 & 0 & 5,15 & Sangat Tinggi \\
\hline 7 & Penambahan nutrisi & 8 & 17 & 5 & 0 & 0 & 5,15 & \\
\hline
\end{tabular}

\section{Kesimpulan}

Berdasarkan hasil kegiatan yang telah dilaksanakan, maka dapat diambil kesimpulan, yang mana pembagian Kuesioner dibagikan kepada 30 orang warga Dusun Seimbang, Desa Pringgabaya, Kecamatan Pringgabaya. Dari jawaban kuesioner tersebut bahwa warga yang memiliki pemahaman awal tentang Hidroponik tergolong rendah. Keefektifan penggunaan pekarangan rumah untuk budidaya sayur mayur yang tergolong sangat tinggi. Kepraktisan dan keefektifan tergolong tinggi. Gangguan hewan peliharaan di pekarangan rumah yang tergolong sedang. Pemanfaatan metode WISH tergolong sedang. Keinginan untuk melanjutkan dan mencoba Kembali budidaya sayur mayur dengan metode hidroponik WISH yang tergolong sangat tinggi. Percepatan pertumbuhan dengan penambahan nutrisi yang tergolong sangat tinggi.

\section{Ucapan Terima Kasih}

Terima kasih kami ucapkan kepada Dosen Pembimbing Lapangan yang sudah memberikan pengarahan terkait pelaksanaan Program Kerja Hidroponik oleh Mahasiswa KKN Tematik

Universitas Mataram tahun 2021. Terimakasih kami ucapkan kepada seluruh aparat Desa Pringgabaya, Kecamatan Pringgabaya, Kabupaten 
Lombok Timur, serta Kepala Wilayah (KAWIL) Dusun Seimbang yang telah memfasilitasi terselenggaranya kegiatan penelitian ini dengan baik dari awal hingga selesai.

\section{Daftar Pustaka}

Atmira, Sariwati. (2019). Pelatihan Pemanfaatan Limbah Botol Plastik Sebagai Media Pertumbuhan Tanaman Hidroponik. Journal of Community Engagement and Empowerment 1 (1), 6-13.

Committee on World Food Security (CFS). (2005). Assessment of the World Food Security Situation. Roma.

D'Anna, Christina. (2019). 'Wick System Hydroponic Gardens'. Diakses pada Tanggal 15 Agustus 2021. The Spruce, terdapat di URL: https://www.thespruce.com/hydroponicgardens-wick-system-1939222.

Devereux, S. Dan Maxwell, S, eds. (2001). Food Security in Sub-Saharan Africa. London: ITDG.

Kementrian Pertanian. (2020). Stok Pangan di Lombok Timur Terus Menumpuk Karena Panen. Jakarta. Kementerian Pertanian Republik Indonesia.

Max. (2021). 'Hydroponic Wick Systems: The Training Wheels of The Hydroponic World'. Diakses pada Tanggal 15 Agustus 2021. Trees, terdapat di URL: https://www.trees.com/gardening-andlandscaping/hydroponic-wick-systems.

Stamoulis, K., Zezza, A. (2003). A Conceptual Framework for National Agricultural, Rural Development, and Food Strategies and Policies. ESA Working Paper No. 03-17.

Syafnidawaty. (2020). 'Perbedaan Data Primer dan Data Sekunder'. Diakses pada Tanggal 7 Juli 2021. Raharja, terdapat di URL: https://raharja.ac.id/2020/11/09/perbedaan-dataprimer-dan-data-.

Syafnidawaty. (2020). 'Perbedaan Penelitian Kualitatif dan Penelitian Kuantitatif'. Diakses pada Tanggal 7 Juli 2021. Raharja, terdapat di URL: https://raharja.ac.id/2020/10/30/perbedaanpenelitian-kualitatif-dan-penelitian-kuantitatif/.

World Bank. (1986). Poverty and Hunger: Issues and Options for Food Security in Developing Countries. Washington DC. 